Supporting information

\title{
Importance of Direct Spin-Spin Coupling and Spin-Flip \\ Excitations for the Zero-Field Splittings of Transition Metal \\ Complexes: A Case Study
}

\author{
Frank Neese \\ Institut für Physkalische und Theoretische Chemie \\ Universität Bonn \\ Wegelerstr. 12 \\ 53115 Bonn \\ Germany \\ phone: $+49-228-732351$ \\ fax: +49-228-739064 \\ e-mail: theochem@thch.uni-bonn.de \\ phone: +49-228-73-2351 \\ fax: +49-228-73-9064
}


Coordinates used for $\mathrm{Mn}(\mathrm{acac})_{3}$ (in Angström)

\begin{tabular}{|c|c|c|c|}
\hline $\mathrm{Mn}$ & 0.145299 & -0.031730 & -0.032561 \\
\hline 0 & 0.421293 & 1.821477 & $\odot .947448$ \\
\hline 0 & -1.056126 & ๑. 872770 & -1.253524 \\
\hline 0 & -0.319537 & -1.827727 & -1.043162 \\
\hline 0 & -1.333000 & -0.423410 & 1.201297 \\
\hline 0 & 1.311774 & -0.941982 & 1.20389 \\
\hline 0 & 1.641610 & ๑. 389072 & -1.238366 \\
\hline C & -0.132336 & 3.956512 & 1.795 \\
\hline C & -0.339957 & 2.811417 & 0.8444 \\
\hline C & -1.346667 & 2.919718 & -0.11733 \\
\hline C & -1.640787 & 1.989704 & -1.08845 \\
\hline C & -2.712213 & 2.259133 & -2.104527 \\
\hline C & -1.583409 & -3.665216 & -1.82101 \\
\hline C & -1.359009 & -2.529868 & -0.85466 \\
\hline C & -2.311241 & -2.311433 & 0.16750 \\
\hline C & -2.252369 & -1.321139 & 1.112310 \\
\hline C & -3.330057 & -1.253460 & 2.1917 \\
\hline C & 3.207421 & -1.843420 & 2.2385 \\
\hline C & 2.570451 & -1.068370 & 1.10322 \\
\hline C & 3.346155 & -0.560387 & 0.0441 \\
\hline C & 2.875397 & ๑. 135828 & -1.0538 \\
\hline C & 3.813838 & $\odot .702358$ & -2.1249 \\
\hline $\mathrm{H}$ & -0.779996 & 3.850349 & 2.4892 \\
\hline $\mathrm{H}$ & ๑. 553286 & 3.943405 & 2.1534 \\
\hline $\mathrm{H}$ & -0.334285 & 4.860907 & 1.3394 \\
\hline $\mathrm{H}$ & -1.920504 & 3.686476 & -0.1278 \\
\hline $\mathrm{H}$ & -3.476761 & 1.627649 & -1.81108 \\
\hline $\mathrm{H}$ & -3.047066 & 2.928772 & -1.936178 \\
\hline $\mathrm{H}$ & -2.329015 & 2.331931 & -3.031703 \\
\hline $\mathrm{H}$ & -0.960682 & -4.120919 & -1.878796 \\
\hline $\mathrm{H}$ & -2.310537 & -4.209362 & -1.59723 \\
\hline $\mathrm{H}$ & -2.030201 & -3.264333 & -2.664580 \\
\hline $\mathrm{H}$ & -3.050653 & -2.908321 & 0.270672 \\
\hline $\mathrm{H}$ & -2.990720 & -1.133583 & 2.954556 \\
\hline $\mathrm{H}$ & -3.918536 & -0.583205 & 2.040007 \\
\hline $\mathrm{H}$ & -3.863521 & -2.099438 & 2.24175 \\
\hline $\mathrm{H}$ & 3. 232257 & -2.768248 & 2.199828 \\
\hline $\mathrm{H}$ & 4.134327 & -1.842299 & 2.192483 \\
\hline $\mathrm{H}$ & 2.816134 & -1.654744 & 3.02603 \\
\hline $\mathrm{H}$ & 4.213640 & -0.714677 & 0.02405 \\
\hline $\mathrm{H}$ & 3.220740 & 1.057053 & -3.05315 \\
\hline $\mathrm{H}$ & 4.124517 & 1.561242 & -1.915245 \\
\hline $\mathrm{H}$ & 4.463935 & ๑. 285611 & -2.20489 \\
\hline
\end{tabular}

